\title{
Simultaneous Effect of Organic Modifier and Physicochemical Parameters of Barbiturates on their Retention on a Narrow-Bore PGC Column. Part 2
}

\author{
Tibor Cserháti and Maria Szőgyi* \\ Research Institute of Materials and Environmental Chemistry, Chemical Research Centre, \\ Hungarian Academy of Sciences, P.O. Box 17, 1525 Budapest, Hungary
}

RECEIVED OCTOBER 27, 2009; REVISED FEBRUARY 18, 2011; ACCEPTED MARCH 23, 2011

\begin{abstract}
The retention time of 23 barbituric acid derivatives was determined on an narrow-bore porous graphitized carbon (PGC) column employing water-dioxane mixtures as mobile phases. The retention factor $(k)$, theoretical plate number $(N)$, and asymmetry factor (AF) were computed for each analyte in each mobile phase. Quantitative structure-retention relationship (QSRR) calculations using stepwise regression analysis (SRA) demonstrated the binding of analytes to the surface of PGC stationary phase is influenced by electrostatic interaction and sterical correspondence between the stationary phase and the various substructures of barbituric acid derivatives. (doi: 10.5562/cca1639)
\end{abstract}

Keywords: barbiturates, porous graphitized carbon, quantitative structure-retention relationship

\section{INTRODUCTION}

Barbituric acid derivatives show a high variety of biological activities. Thus, it has been recently reported that they can trigger transient local amnesia, ${ }^{1}$ inhibit reverse transcription-PCR, ${ }^{2}$ cause brain and body temperature homeostasis, ${ }^{3}$ influence the electrooxidation of 4 -methylcatechol ${ }^{4}$ and are metabolised by $\mathrm{N}$-glucosidation. ${ }^{5}$

Because of their marked significance in human and veterinary health care a considerable number of chromatographic methods has been developed and successfully applied for their separation and quantitative determination in various complex matrices.

A direct immersion solid-phase microextraction coupled to gas chromatography-mass spectrometry was employed for the simultaneous determination of barbiturates in human biological fluid ${ }^{6}$ Other various HPLC technologies have also been used for the analysis of barbiturates. $^{7,8}$ The optimal separation conditions of barbiturates in capillary electrochromatography, ${ }^{9}$ in micellar liquid chromatography, ${ }^{10}$ biopartitioning micellar chromatography, ${ }^{11}$ and in microemulsion electrokinetic chromatography ${ }^{12}$ has been studied in detail.

Quantitative Structure-Retention Relationship (QSRR) studies have been frequently used in each field of chromatographic research to find the theoretical background of separation phenomena, to facilitate the optimisation of concrete separation problems and to define the physicochemical and/or physical processes responsible for the retention characteristics of a homogenous or non-homogenous set of analytes.

Linear and multiple linear regression analyses have been extensively used in QSRR calculations to find the relationship between one dependent (generally a retention parameter) and one or more independent variables (generally molecular characteristics of the analytes). These linear QSRR methods have been recently employed in chromatography for the investigation of the molecular mechanism of separation, ${ }^{13}$ for the classification of modern stationary phases, ${ }^{14}$ for structure-retention relationship study in $\mathrm{HPLC}^{15}$ and in $\mathrm{GC},{ }^{16,17}$ and for the elucidation of the correlation between retention and biological activity. ${ }^{18}$ Stepwise regression analysis (SRA) is an up-to-date version of multivariate linear regression analysis. In the traditional multivariate regression analysis, the presence of independent variables that exert no significant influence on the dependent variable decreases the significance level of the independent variables that significantly influence the dependent variable. SRA overcomes this difficulty by automatically eliminating from the selected equation the insignificant independent variables enhancing in this manner the information power of the calculation. ${ }^{19}$

\footnotetext{
* Author to whom correspondence should be addressed. (E-mail: szogyim@t-online.hu)
} 
Table 1. Chemical structure of barbituric acid derivatives

\begin{tabular}{|c|c|c|c|c|c|}
\hline Compound No. & $\mathrm{R} 1$ & $\mathrm{R} 2$ & R3 & $\mathrm{R} 4$ & $\mathrm{X}$ \\
\hline 1 & allyl & 1-methylbutyl & $\mathrm{H}$ & $\mathrm{H}$ & $\mathrm{S}$ \\
\hline 2 & ethyl & 1,3-dimethylbutyl & $\mathrm{H}$ & $\mathrm{H}$ & $\mathrm{S}$ \\
\hline 3 & ethyl & phenyl & $\mathrm{H}$ & $\mathrm{H}$ & $\mathrm{O}$ \\
\hline 4 & ethyl & ethyl & phenyl & $\mathrm{H}$ & $\mathrm{O}$ \\
\hline 5 & ethyl & ethyl & benzoyl & $\mathrm{H}$ & $\mathrm{O}$ \\
\hline 6 & ethyl & ethyl & benzoyl & Benzoyl & $\mathrm{O}$ \\
\hline 7 & ethyl & ethyl & p-Cl-benzoyl & $\mathrm{H}$ & $\mathrm{O}$ \\
\hline 8 & ethyl & ethyl & p-NO ${ }_{2}$-benzoyl & $\mathrm{H}$ & $\mathrm{O}$ \\
\hline 9 & ethyl & ethyl & $\mathrm{p}$ - $\mathrm{NO}_{2}$-benzoyl & $\mathrm{p}-\mathrm{NO}_{2}$-benzoyl & $\mathrm{O}$ \\
\hline 10 & ethyl & phenyl & phenyl & $\mathrm{H}$ & $\mathrm{O}$ \\
\hline 11 & ethyl & phenyl & benzoyl & methyl & $\mathrm{O}$ \\
\hline 12 & ethyl & phenyl & $\mathrm{p}-\mathrm{NH}_{2}$-benzoyl & methyl & $\mathrm{O}$ \\
\hline 13 & ethyl & phenyl & $\mathrm{o}-\mathrm{NO}_{2}$-benzoyl & methyl & $\mathrm{O}$ \\
\hline 14 & ethyl & phenyl & $\mathrm{p}-\mathrm{NO}_{2}$-benzoyl & methyl & $\mathrm{O}$ \\
\hline 15 & ethyl & phenyl & $\mathrm{m}-\mathrm{NO}_{2}$-benzoyl & methyl & $\mathrm{O}$ \\
\hline 16 & ethyl & ethyl & $\mathrm{p}-\mathrm{NO}_{2}$-benzoyl & methyl & $\mathrm{O}$ \\
\hline 17 & ethyl & ethyl & benzoyl & $\mathrm{H}$ & $\mathrm{O}$ \\
\hline 18 & methyl & phenyl & benzoyl & $\mathrm{H}$ & $\mathrm{O}$ \\
\hline 19 & methyl & phenyl & benzoyl & methyl & $\mathrm{O}$ \\
\hline 20 & methyl & phenyl & benzoyl & $\mathrm{H}$ & $\mathrm{O}$ \\
\hline 21 & ethyl & methyl & $\mathrm{H}$ & $\mathrm{H}$ & $\mathrm{O}$ \\
\hline 22 & ethyl & ethyl & propyl & $\mathrm{H}$ & $\mathrm{O}$ \\
\hline 23 & methyl & methyl & methyl & $\mathrm{H}$ & $\mathrm{O}$ \\
\hline
\end{tabular}

The aim of the study was the measurement of the retention parameters (retention factor, theoretical plate number and asymmetry factor) of a set of barbiturates on a narrow bore PGC column in water-dioxane mobile phases, the assessment of the simultaneous impact of organic modifier and physicochemical parameters of analytes on the retention characteristics applying stepwise regression analysis (SRA) and the comparison of the results with those previously obtained using another set of barbituric acid derivatives as model compounds. ${ }^{20}$

\section{EXPERIMENTAL}

\section{Chemicals}

Dioxane of HPLC quality was purchased from Romil Ltd. (Cambridge, UK). The use of dioxane as organic modifier was motivated by the fact that the separation parameters of dioxane differ considerable on the retention characteristics of other frequently employed organic modifiers (methanol, acetone, acetonitrile, etc.). The application of dioxane may result in different separation characteristics of the system. The application of 48-35\% $(v / v)$ dioxane concentrations were applied because the barbiturate derivatives show measurable retention times in these binary mobile phases. The chemical structures of barbituric acid derivatives are listed in Table 1.

\section{Chromatographic Conditions}

The solutes were separately dissolved in the mobile phases at a concentration of $1.0 \mathrm{mg} / \mathrm{ml}$ and $0.5 \mu \mathrm{l}$ was injected into the column. Determination of retention times was carried out with a Waters LC Module HPLC device with a variable volume injector and a Waters 746 Data Modul integrator (Waters-Millipore Inc., Milford, Massachusetts, USA). Measurements were performed 
Table 2. Parameters of significant relationships between the retention parameters and physicochemical characteristics of barbituric acid derivatives

\begin{tabular}{cccc}
\hline Parameter & Equation 1 & Equation 2 & Equation 3 \\
\hline$a$ & 28.29 & 23549 & 0.813 \\
$b_{1}$ & -0.36 & -29251 & 0.550 \\
$s_{b_{1}}$ & 0.14 & 10841 & 0.20 \\
$s_{2}$ & 15.36 & - & -0.288 \\
$s_{b_{2}}$ & 2.03 & - & 0.05 \\
$b_{3}$ & -22.85 & - & 0.148 \\
$s_{b_{3}}$ & 6.16 & - & 0,03 \\
$b_{1}^{\prime}(\%)$ & 18.39 & - & 6.27 \\
$b_{2}^{\prime}(\%)$ & 54.79 & - & 44.95 \\
$b_{3}^{\prime}(\%)$ & 26.82 & - & 48.78 \\
$r^{2}(\%)$ & 40.65 & 5.08 & 20.47 \\
$f_{\text {calc. }}$ & 30.65 & 7.28 & 11.49 \\
$f_{95 \%}$ & 2.68 & 3.92 & 2.68 \\
\hline
\end{tabular}

Results of stepwise regression analysis. For symbols see original manuscript. ( $n=138 ; C$ is the concentration of dioxane in the mobile phase, vol. \%).

$$
\begin{aligned}
& k=a+b_{1} \cdot C+b_{2} \cdot F+b_{3} \cdot R \\
& N=a+b_{1} \cdot R \\
& \mathrm{AF}=a+b_{1} \cdot R+b_{2} \cdot B_{1}+b_{3} \cdot B_{4}
\end{aligned}
$$

on a Hypersil Hypercarb PGC column $(100 \mathrm{~mm} \times 2.1$ mm I.D., particle size, $7 \mu \mathrm{m}$ ) (HYPERSIL, Runcorn, Cheshire). Analyses were carried out at room temperature $\left(21 \pm 1^{\circ} \mathrm{C}\right)$ without thermostating the column. Water-dioxane mixtures with dioxane volume fractions of $52,55,57,60$, and $65 \%(v / v)$ were used as mobile phases. The flow rate was in each instance $0.10 \mathrm{ml} / \mathrm{min}$, analytes were detected at $240 \mathrm{~nm}$. Each measurement was performed in triplicate and the retention factor $(k)$, the theoretical plate number $(N)$ and asymmetry factor (AF) were calculated separately for each barbituric acid derivative in each eluent system. The dead volume of the HPLC system was measured by three parallel injections on $0.1 \%$ aqueous $\mathrm{NaNO}_{2}$.

\section{Stepwise Regression Analysis}

The simultaneous impact of the composition of mobile phase and the physicochemical characteristics of analytes of the retention parameters were assessed by SRA. SRA has been performed three times the dependent variables being the retention factor, theoretical plate number, and asymmetry factor of the 23 barbiturates determined at six different concentrations of organic modifier (altogether 138 observations). The independent variables were in each instance the actual vol- ume fraction of dioxane in the mobile phase and the following physicochemical characteristics of analytes: $\pi=$ Hansch-Fujita's substituent constants characterising hydrophobicity; H-Ac and H-Do = indicator variables for proton acceptor and proton donor properties, respectively; $\mathrm{M}-\mathrm{RE}=$ molar refractivity; $F$ and $R=$ Swain and Luton's electronic parameters characterizing the inductive and resonance effects; $\sigma=$ Hammett's constant characterising the electron-withdrawing power of the substituents at meta and para+ortho positions; $\mathrm{E}_{\mathrm{s}}=$ Taft's constant characterising the steric effects of substituents; $B_{1}$ and $B_{4}=$ Sterimol width parameters determined by distance of substituents at their maximum point perpendicular to attachment. Physicochemical parameters were calculated according to the additivity rule from the fragmental constants. Fragmental constants are physicochemical parameters characterising simple molecular substructures without taking into consideration the possible intramolecular interactions among the substructures in the molecule.

The selection of this set of physicochemical parameters was motivated by the fact that they previously found application in QSRR studies. Thus, M-RE for the assessment of the relationship between structure and retention of solutes on polybutadiene-coated alumina stationary phase, ${ }^{21}$ for the study of the impact of lipophilicity and polarity parameters in HPLC, ${ }^{22}$ and diverse electronic and steric parameters for QSRR studies in both $\mathrm{GC}^{23,24}$ and HPLC. ${ }^{25}$

The number of accepted independent variables was not limited, the limit of acceptance was set to $95 \%$ significance level. The inclusion of the concentration of organic modifier into the set of independent variables consisting of physicochemical parameters of solutes was motivated by the following considerations: it has been previously proved that barbituric acid derivatives display regular retention behaviour on PGC stationary phase (their retention decreases monotonously with increasing amount of organic modifier in the eluent system). Moreover, it can be supposed that the retention of this class of solutes depends not only on the dioxane concentration but also on their physicochemical characteristics. Therefore, their common inclusion in the calculation as independent variables is justified. This procedure makes possible the determination and comparison of the relative impact of dioxane concentration and those of physicochemical parameters of analytes on the retention.

QSRS calculations generally apply the retention time, retention factor or the logarithm of retention factor as dependent variables. Interestingly, the number of studies dealing with the elucidation of the quantitative relationship between other retention parameters such as theoretical plate number and asymmetry factor is suprisingly low. 
Software for SRA was purchased from Compudrug Ltd. (Budapest, Hungary).

\section{RESULTS AND DISCUSSION}

As excepted barbituric acid derivatives exposed regular retention behaviour on PGC column their retention time: their retention time were decreasing with increasing volume fraction of organic modifier in the mobile phase. The high differences among the retention times of barbiturates indicate that these solutes can be easily separated on narrow-bore PGC column. The fact that the other calculated retention characteristics (asymmetry factor and theoretical plate number) showed also marked deviations between the analytes justifies their inclusion in the QSRR computations.

Significant linear correlations were found between the retention parameters and physicochemical characteristic of barbiturates. The parameters of the significant equations are compiled in Table 2. The significance level was over $95 \%$ in each instance demonstrating that the physicochemical parameters included in the QSRR calculations exert a considerable influence on the retention behaviour of barbiturates (compare calculated and tabulated $F$ values). However, the ratio of variance explained was relatively low (see $r(\%)$ values). This finding can be tentatively explained by the supposition that other physicochemical characteristics not included in the QSRR computations may also exert a significant influence on the retention of this class of analytes. According to the results of SRA the retention factor and asymmetry factor depended on more than one independent variables (see Equations 1 and 3). The linear dependence of the retention factor on the volume raction of organic modifier proves again the regular retention behaviour of barbituric acid derivatives on PGC column. The significant impact of electronic parameters $F$ and $R$ on the retention factor suggests that the interaction between the active centres of the stationary phase and the polar substructures of barbiturates is mainly of electrostatic. Interestingly, the normalised slope values (path coefficients $b_{\mathrm{i}}^{\prime}$ values) indicate that the impact of electronic parameters on the retention is stronger than that of the volume fraction of organic modifier. Similarly to the retention factor these two chromatographic parameters (theoretical plate number and asymmetry factor) also depend significantly on the electronic parameter $R$. This finding suggests again that electrostatic interactions between the analytes and stationary phase play a considerable role in the binding of barbituric acid derivatives to the PGC surface. The concentration of dioxane does not influence significantly the $\mathrm{N}$ and AF values indicating that these two retention parameters are not modified by the concentration of organic modifier in the mobile phase. The significant impact of sterical parameters on the asymmetry factor (see Equation 3) can be explained by the supposition that the ring of barbiturates bind to the hexagonal graphitic substructures on the PGC surface modifying peak symmetry.

The results of the present QSRR computations are markedly different from those obtained by using different set of barbituric acid derivatives. ${ }^{20}$ This discrepancy draws the attention to the fact that the selection of analytes with identical basic structures but different substituents may influence the results of QSRR calculations. It also suggests that the extrapolation of results obtained with one set of analytes can not be automatically transferred to other set of analytes of identical basic structure characteristics.

\section{CONCLUSIONS}

The results illustrated that SRA can be successfully applied for the assessment of the correlation between the retention characteristics of barbiturates on a narrowbore PGC column and their physicochemical parameters. Calculations demonstrated the influence of electrostatic interactions and sterical correspondence between the analytes and the surface of stationary phase on the retention factor, theoretical plate number and asymmetry factor. The comparison of results with other ones obtained by employing other set of barbituric acid derivatives indicated the marked effect of the character of substituents on the results of QSRR calculations

\section{REFERENCES}

1. T. Benke, A. Chemelli, C. Lottersberger, P. Waldenberger, E. Karen, and E. Trunk, Epilepsi \& Behav. 6 (2005) 274-278.

2. C. Hyun, L. J. Filippich, and I. Hughes, J. Biochem. Biophys. Meth. 62 (2005) 63-68.

3. E. A. Kiyatkin and P. L. Brown, Physiol. \& Behav. 84 (2005) 563-570.

4. D. Nematollahi and E. Tammari, Electrochim. Acta 50 (2005) 3648-3654.

5. K. Toide, Y. Terauchi, T. Fujii, H. Yamazaki, and T. Kamataki, Biochem. Pharmacol. 67 (2004) 1269-1278.

6. M. Iwai, H. Hattory, T. Arinobu, A. Ishii, T. Kumazawa, H. Noguchi, H. Noguchi, O. Suzuki, and H. Seno, J. Chromatogr. B 806 (2004) 65-73.

7. Y. Martin-Biosca, S. Sagrado, R. M. Villanueva-Camanas, and M. J. Medina-Hernandez, J. Pharm. Biomed. Anal. 21 (1999) 331-338.

8. P. F. Garcia-Borregon, M. Lores, and R. Cela, J. Chromatogr. A 870 (2000) 39-44.

9. K. Ohyama, M. Wada, Y. Ohba, O. Fujishita, K. Nakashima, and N. Kuroda, Biomed. Chromatogr. 18 (2004) 396-399.

10. J. Esteve-Romero, S. Carda-Broch, M. Gil-Agusti, M.-E. Capella-Peiró, and D. Bose, TrAC 24 (2005) 75-91.

11. L. Escuder-Gilabert, S.Sagrado, R. M. Villanueva-Camanas, and M. J. Medina-Hernández, Biomed. Chromatogr. 91 (2005) 155-168.

12. R. Iqbal, S. A. A. Rizvi, C. Akbay, and S. A. Shamsi, J. Chromatogr. A 1043 (2004) 291-302.

13. M. A. Al-Haj, R. Kaliszan,and A. Nasal, Anal. Chem. 71 (1999) 2976-2985. 
14. R. Kaliszan, M. A. van Straaten, M. Markuszewski, C. A. Cramers, H. A.and Claessens, J. Chromatogr. A 855 (1999) 455-486.

15. V. Andrisano, C. Bertucci, V. Cavrini, M. Recatini, A. Cavalli, L. Veroli, G. Felix, and I. W. Wainer, J. Chromatogr. A 876 (2000) 75-86.

16. O. Ivaniuc, T. Ivanciuc, D. Cabrol-Bass, and A. T. Balaban J. Chem. Inf. Comput. Sci 40 (2000) 732-743.

17. R. Acuna-Cueva, F. Hueso-Urena, N. A. J. Cabeza, S. B. Jimenez-Pulido, M. N. Moreno-Carretero, and J. M. M. Martos, J. Am. Chem. Soc. 77 (2000) 627-631.

18. M. P. Monatana, N. B. Pappano, N. B. Debattista, J. Raba, and J. M. Luco, Chromatographia 51 (2000) 727-735.
19. H. Mager, Moderne Regressionsanalyse, Salle, Sauerlander, Frankfurt am Main, (1982) 135-167.

20. E. Forgács, T. Cserháti, I. Miksik, A. Ekchardt, and Z. Deyl, J. Chromatogr. B $\mathbf{8 0 0}$ (2004) 259-262.

21. R. Kaliszan, K. Osmialowski, B. J. Bassler, and R. A. Hartwick, J. Chromatogr. 499 (1990) 333-344.

22. P. Jandera, J. Fischer, J. Jebavá, and P. Rezac, Chromatographia 56 (2002) S95-S102.

23. T. F. Woloszyn, and P. C. Jurs, Anal. Chem. 64 (1992) 3059-3063.

24. O. Mekenyan, N. Dimov, and V. Enchev, Anal. Chim. Acta 260 (1992) 69-74.

25. $\quad$ P. Jandera, J. Chromatogr. A 656 (1993) 437-467. 